\title{
The Replacement of Gypsum by Barite and Celestite
}

\author{
PABLO FORJANES ${ }^{1 *}$, JOSÉ MANUEL ASTILLEROS ${ }^{1,2}$ AND \\ LURDES FERNÁNDEZ DÍAZ ${ }^{1,2}$
}

${ }^{1}$ Dpt. of Mineralogy and Petrology. Complutense University. Madrid, Spain (correspondance: pforjane@ucm.es)

${ }^{2}$ Institute of Geosciences (CSIC, UCM), Madrid, Spain

Barite $\left(\mathrm{BaSO}_{4}\right)$ and celestite $\left(\mathrm{SrSO}_{4}\right)$ are relevant industrial minerals which are the end members of a nearly ideal solid solution. Celestite is only exploited from massive sedimentary deposits associated to evaporites, where celestite origin is linked to replacement processes after the interaction of calcium sulphates, namely gypsum and anhydrite, with Srbearing aqueous solutions [1]. Barite deposits, on the other hand, are found in a plethora of geological environments, including those where it forms through gypsum and/or anhydrite replacement processes.

In this work we aim to better understand the processes that lead to the formation of barite and celestite in sedimentary basins after the interaction of gypsum with Ba or Sr-bearing aqueous solution, respectively. Our results evidence that the interaction of gypsum with Sr-bearing aqueous solution leads to the development of a coupled dissolution-crystallization reaction, which results in the rapid formation of porous celestite pseudomorphs after gypsum. The reaction progress is facilitated by the formation of a network of interconnected porosity that balances the negative molar volume change $\left(-27.1 \mathrm{~cm}^{3} / \mathrm{mol}\right)$ involved in the gypsum into celestite transformation. In contrast, the interaction of gypsum with a Ba-bearing aqueous solution only leads to the replacement of a most external rim of the gypsum by barite platy crystals. Although the barite into gypsum transformation also involves a negative molar volume change $\left(-22.2 \mathrm{~cm}^{3} / \mathrm{mol}\right)$, the textural relationships between barite crystals in this rim result in an effectivey armouring of the gypsum core, thereby preventing the progress of the reaction.

Our results higlight the relevance of textural features in the development of coupled dissolution-crystallization reactions. Furthermore, they provide a reasonable explanation for the rarity of large barite deposits linked to evaporites [2].

[1] Hanor (2004). J. Sediment. Res. 74. 168-175

[2] Forjanes et al. (2020). Minerals. 10.189 